A N N A L E S Annales de Bretagne et des Pays de l'Ouest

\title{
LE HUËROU, Armelle (éd. et trad.), Baudri de Bourgueil. Euvres en prose
}

Lucile Tranduc

\section{(2) OpenEdition}

Journals

Édition électronique

URL : http://journals.openedition.org/abpo/3075

DOI : $10.4000 /$ abpo.3075

ISBN : 978-2-7535-4275-4

ISSN : 2108-6443

Éditeur

Presses universitaires de Rennes

Édition imprimée

Date de publication : 30 juin 2015

Pagination : 155-157

ISBN : 978-2-7535-4273-0

ISSN : 0399-0826

Référence électronique

Lucile Tranduc, « LE HUËrou, Armelle (éd. et trad.), Baudri de Bourgueil. EFuvres en prose », Annales de Bretagne et des Pays de l'Ouest [En ligne], 122-2 | 2015, mis en ligne le 30 juin 2015, consulté le 23 septembre 2020. URL : http://journals.openedition.org/abpo/3075 ; DOI : https://doi.org/10.4000/ abpo.3075

Ce document a été généré automatiquement le 23 septembre 2020

(c) Presses universitaires de Rennes 


\title{
LE HUËROU, Armelle (éd. et trad.), Baudri de Bourgueil. CEuvres en prose
}

\author{
Lucile Tranduc
}

\section{RÉFÉRENCE}

LE HuËROU, Armelle (éd. et trad.), Baudri de Bourgueil. CEuvres en prose (textes

hagiographiques), t. III, Paris, Les Belles Lettres, 2013 (Auteurs latins du Moyen Âge).

1 L'ouvrage d'Armelle Le Huërou, paru aux Belles Lettres en 2013, dans la collection Auteurs latins du Moyen Âge, fait suite aux tomes I et II édités par Jean-Yves Tilliette et consacrés aux poèmes de Baudri de Bourgueil (1045-1130) (Tilliette J.-Y. (éd. et trad.), Baudri de Bourgueil. Poèmes, Paris, les Belles Lettres, t. I-II, 1998-2002, Auteurs latins du Moyen Âge). Il contient l'édition scientifique et la traduction des cinq œuvres hagiographiques en prose composées par l'archevêque de Dol (1107-1130). Ce recueil s'ouvre d'abord sur trois textes originaux. La Relatio de scuto et gladio sancti Michaelis (BHL 5953) rédigée peu de temps après 1112, année de l'incendie du sanctuaire auquel Baudri de Bourgueil fait référence, relate la translation au Mont Saint-Michel d'une épée et d'un écu miniatures réputés avoir appartenu à l'archange (p. 1-41).

2 L'Historia magistri Roberti fundatoris Fontis Ebraudi (BHL 7259), composée peu après la mort de Robert d'Arbrissel (1116) à la demande de l'abbesse de Fontevraud, Pétronille de Chemillé (1115-1149), retrace la trajectoire du fondateur du monastère mixte, d'Arbrissel à Fontevraud (p.43-97). Les Miracula sancti Valentini (BHL 8461), datés des alentours de 1120, sont destinés aux moines de Jumièges (p. 99-161). Cette collection de miracles collectifs et de miracles thérapeutiques individuels, précédée d'un bref récit de translation, vise à expliquer la présence du chef d'un martyr réputé enseveli à Rome dans l'abbaye de la vallée de la basse Seine. Suivent ensuite deux réécritures. La Vita beati Hugonis (BHL 4033), consacrée à Hugues, bâtard supposé de Charlemagne, évêque de Rouen (722-730), Bayeux et Paris, abbé de Jumièges et Fontenelle (p. 163-241), est elle aussi composée pour les religieux de Jumièges, à la demande de l'abbé Ours 
(1101-1127). La Vita sancti Sansonis (BHL 7486), qui retrace le parcours de Samson de la Bretagne insulaire jusqu'à Dol où il fonde un monastère, se présente comme l'actualisation stylistique et formelle d'une Vita carolingienne (p. 243-435).

3 L'ouvrage d'Armelle Le Huërou présente un double intérêt. Il permet tout d'abord de redécouvrir un aspect méconnu de l'œuvre de Baudri de Bourgueil. Ces textes hagiographiques, éclipsés par les poèmes édités par Jean-Yves Tilliette, n'avaient jusque là fait l'objet que de publications lacunaires, éparses et vieillies. La Vita sancti Sansonis restait même inédite. Ensuite, les introductions qui précédent ces œuvres retracent leur histoire et se proposent de faire le point sur les circonstances ainsi que les modalités de leur composition, les enjeux dont elles sont porteuses, leur réception et leurs conditions de transmission ( $\mathrm{p}$. xxvI). En d'autres termes, les analyses d'Armelle Le Huërou mettent en lumière les logiques idéologiques et politiques de l'entreprise de Baudri de Bourgueil.

4 Ainsi, la Relatio de scuto et gladio sancti Michaelis vise, d'une part, à lancer le culte du glaive et de l'écu miniatures conservés au Mont Saint-Michel et, d'autre part, à réécrire le passé du sanctuaire normand afin d'établir sa primauté sur le Monte Gargano. Les Miracula sancti Valentini obéissent à des impératifs similaires puisqu'il s'agit d'authentifier la relique détenue par les moines de Jumièges, de réactiver et de promouvoir le culte du martyr romain qui figure au rang des patrons de l'abbaye depuis 1052. Les Vitae beati Hugonis et sancti Sansonis permettent d'étudier les logiques qui sous-tendent le processus de réécriture hagiographique. Certes, Baudri de Bourgueil se livre à une réfection formelle et stylistique de ces deux textes, au moyen d'une réduction par concision et d'un renouvellement stylistique dans le cas de la Vita beati Hugonis et au moyen d'une transtylisation et d'une réduction par élimination de longs passages à vocation édifiante dans celui de la Vita sancti Sansonis.

5 Néanmoins, l'analyse faite par Armelle Le Huërou, inspirée par les travaux de Monique Goullet sur les entreprises de réécriture hagiographique au Moyen Âge, contribue à démontrer qu'avec ces récits, l'archevêque de Dol compose en réalité deux œuvres fort personnelles. La Vita sancti Sansonis est en effet traversée par des enjeux politiques modifiant le contenu, le sens et la portée des textes précédents. En actualisant la figure de Samson, Baudri de Bourgueil cherche à faire de son héros le premier archevêque de « toute la Bretagne » dont Dol est la métropole. Grâce au parallèle établi avec sa propre personne, l'hagiographe peut étendre le caractère transmissible de l'archiepiscopus de Samson à tous ses successeurs.

6 Ceci fait écho à la situation de l'archevêché de Dol au XII siècle : si Baudri de Bourgueuil a obtenu le pallium à titre personnel et peut se parer du titre d'archiepiscopatus, il n'est pas en revanche en mesure de garantir ce dernier à son successeur. Le recours à Samson soutient par conséquent les prétentions de Baudri. De même, l'évocation inédite de Pental, enclave normande de Dol, concédée à Samson par le roi Childebert, permet de redéfinir le statut de cette dernière, de faire d'elle une exemption ainsi que le « second siège » du diocèse breton.

7 D'après Armelle Le Huërou, cette Vita sancti Sansonis vise à reconfigurer le diocèse dont Baudri de Bourgueil a la charge autour de cette bipolarisation inédite. Le remaniement littéraire observé justifie de la sorte un remaniement topographique. La Vita beati Hugonis fournit elle aussi à l'archevêque de Dol l'occasion d'établir, dès le prologue, un parallèle entre lui, ancien moine bénédictin devenu archevêque, et son sujet, métropolitain devenu moine bénédictin. D’après Armelle Le Huërou, tous deux « sont 
aux prises avec humilitas et oboedientia, les deux sœurs qui gouvernent la conuersatio des disciples de saint Benoît » (p. 175). C'est également à travers ce prisme qu'elle invite à lire l'Historia magistri Roberti fundatoris Fontis Ebraudi, œuvre originale. Comme dans la Vita beati Hugonis, l'archevêque de Dol manifeste dans ce texte un attachement sans faille à un monachisme bénédictin et cherche à établir la supériorité de la vie monastique. Selon Armelle Le Huërou, ceci laisse penser que l'hagiographe échoue là à saisir et restituer le parcours atypique de Robert d'Arbissel tant celui-ci lui est étranger. Le terme d'échec n'est peut-être pas celui qui convient le mieux. En fait, la conception de la sainteté véhiculée par Baudri de Bourgueil témoigne du refus des moines bénédictins d'intégrer les nouvelles voies de la sainteté qui se développent au $\mathrm{XII}^{\mathrm{e}}$ siècle, de leur attachement à un «âge d'or » du monachisme. De la sorte, l'Historia magistri Roberti n'est sans doute pas tant un échec à saisir la singularité de la trajectoire de Robert d'Arbissel que la participation de l'ancien abbé de Saint-Pierre de Bourgueil à un effort de normalisation bénédictine.

8 À cette réserve près, l'entreprise d'Armelle Le Huërou participe ainsi pleinement au renouvellement des études hagiologiques en cours à l'heure actuelle. Elle s'insère dans les problématiques développées par les historiens abordant ces sources, confirmant que " la matière hagiographique [...] est saturée d'idéologie ", pour reprendre les propos formulés par Monique Goullet dans ses conclusions au colloque de Poitiers (2008). (Goullet M., "Conclusions », dans Bozóky E. (dir.), Hagiographie, idéologie et politique au Moyen Âge en Occident, Actes du colloque international du Centre d'Études supérieures de Civilisation médiévale de Poitiers (11-14 septembre 2008), Turnhout, Brepols, 2012 (Hagiologia, 8), p. 514). 